\title{
CONCEPTUALISING A SYSTEM FOR QUALITY CLINICAL DECISION-MAKING IN NURS- ING
}

\section{Ebin J Arries}

M Cur, Ph D

Senior Lecturer, Department of Nursing Science, Rand Afrikaans University

Corresponding author: ea@edcur.rau.ac.za

\author{
Elzabé Nel \\ M Cur, Ph D \\ Senior Lecturer, Department of Nursing Science, Rand Afrikaans University
}

Keywords: clinical decision-making; quality; rational interaction; standard and system

\begin{abstract}
Quality clinical decision-making in nursing is the essence of quality nursing care delivery. The purpose of this article is to conceptualise a system for quality clinical decision-making in nursing. A system for quality clinical decisionmaking in nursing was conceptualised based on a review of the literature pertaining to clinical decision-making. To that effect, both published and unpublished references were reviewed. The review revealed two predominant theoretical perspectives of the process of clinical decision-making: a positivistic perspective and a postmodernistic perspective. These perspectives are respectively exemplified by an information-processing approach and the intuitive approach to clinical decision-making in nursing. The strengths and weaknesses of both approaches were explored and, as a result, a third theoretical approach emerges: the idea of a dialectic, integrative, interactive approach that culminates in the conceptualisation of a system for quality clinical decision-making in nursing. According to a system for quality clinical decision-making, clinical decision-making is viewed as an open system in which both approaches, described as a "piece-meal" approach (Tabak \& Bar-Tal, 1996:1-2) and an intuitive approach (Benner, 1984) can be used in a complementary manner to achieve quality clinical decisions in nursing. As a feedback mechanism to promote or improve the quality of clinical decisions in nursing, standards for quality clinical decision-making are proposed in an exemplary manner. In addition, a system for quality clinical decisionmaking in nursing capitalises on the heritage of the nursing process. Considering the changes and the complexities associated with clinical decision-making in nursing, the system accommodates recent knowledge development activities in nursing, such as developments in nursing classification systems and the classification of nursingsensitive patient outcomes.
\end{abstract}

\section{OPSOMMING}

Gehalte kliniese besluitneming in verpleging word beskou as die essensie van gehalte verpleegsorg. Die doel van hierdie artikel is om 'n sisteem vir gehalte besluitneming in verpleging te konseptualiseer. Die konseptualisering van 'n sisteem vir gehalte kliniese besluitneming in verpleging is op die bestudering van die literatuur oor kliniese bes/uitneming gegrond. Beide gepubliseerde en ongepubliseerde verwysingsbronne is bestudeer. Twee dominante perspektiewe, 'n positivistiese perspektief en 'n postmodernistiese perspektief, met betrekking tot die proses van kliniese besluitneming is na aanleiding van die bestudering van die literatuur geïdentifiseer. Hierdie perspektiewe word onderskeidelik deur ' $n$ inligtingsverwerkingsbenadering en ' $n$ intuïtiewe benadering tot kliniese bes/uitneming in verpleging beliggaam. Die goeie hoedanighede en tekortkominge van beide benaderings is verken en ' $n$ derde teoretiese benadering het gevolglik tot stand gekom: die idee van 'n dialektiese, geïntegreerde, interaktiewe benadering wat in die konseptualisering van 'n sisteem vir gehalte bes/uitneming in verpleging kulmineer. Volgens ' $n$ sisteem vir gehalte besluitneming in verpleging, word kliniese besluitneming beskryf as ' $n$ stuksgewyse benadering (Tabak \& Bar-Tal, 1996:1-2) en/of ' $n$ intuïtiewe benadering (Benner, 1984), wat op ' $n$ aanvullende wyse aangewend kan word, 
om gehalte besluitneming in verpleging te kan laat plaasvind. Standaarde vir gehalte bes/uitneming, in die vorm van ' $n$ voorbeeld, word as terugvoermeganisme voorgestel, ten einde die gehalte van kliniese besluitneming in verpleging te bevorder en te verbeter. Voorts, kapitaliseer ' $n$ sisteem vir gehalte besluitneming in verpleging op die herkoms van die verpleegproses. Deur die veranderinge en kompleksiteit wat met kliniese besluitneming gepaard gaan, akkommodeer dit resente kennis in verband met ontwikkelingsaktiwiteite in verpleging, soos die ontwikkeling van ' $n$ verpleegklassifikasiesisteem en die klassifikasie van uitkomste ten opsigte van die verpleegsensitiewe-pasiënt.

\section{INTRODUCTION}

Despite its obvious importance in care delivery, clinical decision-making in nursing practice has received little attention. Nurses' decisions influence the lives of individuals, communities and society at large, yet neither research nor nursing education has, until recently, emphasised this area of practice. Current interest in clinical decision-making can be attributed to various factors. Contemporary trends and forces, such as the current transformation of the health care system in South Africa, the increased focus on quality of care, increased awareness among the public about their right to accessible health care and participation in clinical decision-making (Muller, 1996:68-69), decreased resources and budget restrictions (Kilian, 1995:419-420), advanced roles, such as decision-maker, collaborator, consultant (Le Storti, Cullen, Hanzlik, Michiels, Piano, Ryan \& Johnson, 1999:63) and evidence-based practice, suggest that another transformation in the way nurses make clinical decisions is needed. Through advanced roles such as these, nurses will assist in shaping the future health-care environment (Le Storti et al. 1999:63). These changes dictate that clinical decision-making by the nurse of the $21^{\text {st }}$ century must evolve beyond the traditional task-oriented focus to encompass the emerging role orientation (Krejci, 1999:21-29). This will require that nurses move beyond well-defined organisational decision-making boundaries and autonomous professional roles to a more inclusive focus on processes, outcomes and people, by making decisions together in an interactive and interdisciplinary manner (Moorhead \& Huber, 1997:1).

As nurses redesign geographical, functional and relational decision-making boundaries and processes, they will facilitate individuals, groups and communities in moving towards a new reality of client-centred healthcare decision-making. This implies the need for an approach to clinical decision-making that represents its complexity and uncertainty and a focus on interaction and integration. Therefore, it is concluded that if nurses are to be credible participants in shaping the future of health-care delivery and defining their role in a complex, uncertain health-care environment, quality clinical decision-making is imperative.

In view of the above, it is necessary to re-examine the factors that influence quality clinical decision-making in nursing, the processes and outcomes thereof, and to propose a mechanism to improve on the quality of clinical decision-making in nursing. The purpose of the article is therefore to conceptualise a system for quality clinical decision-making in nursing by using a systems perspective. To achieve this purpose, a summary of the state of clinical decision-making is given by reviewing both published and unpublished work that addresses the factors influencing quality clinical decisionmaking, its process and outcomes.

\section{QUALITY CLINICAL DECISION-MAKING}

Clinical decision-making is a prerequisite for all important daily nursing activities, since a decision is a prerequisite for any significant action taken by a nurse. Nurses make two types of decisions related to practice. Firstly, they make decisions that affect the health of patients directly (also called patient-care decisions or clinical decisions) and, secondly, they make condition-of-work (or managerial) decisions that affect the work environment or groups of patients (Krairiksh \& Anthony, 2001:17). Quality clinical decision-making is widely accepted as a critical component of professional nursing practice. It creates a climate for sound interpersonal functioning and may foster quality decisionmaking in health-care delivery (Booyens, 1998:503).

Clinical decision-making in nursing practice has been studied from different theoretical perspectives, including theoretical perspectives of the analytical decision theory (Lilford, Pauker, Braunholtz \& Chard, 1998:405409; Offredy, 1998:989-990; Aspinal, 1979:182-185; 
Hammond, Hursch \& Todd, 1964:438-456) and the information-processing theory (Baker, 1997:43-44; Buckingham \& Adams, 2000:981-983; Higgs \& Jones, 1995:6; Corcoran, 1986:231-236; Tanner, Padrick, Westfall \& Putzier, 1987:358-363). Models of clinical decision-making include the nursing diagnosis process (Gordon, 1994), diagnostic reasoning (Carnavali \& Thomas, 1993) and clinical reasoning (Pesut \& Herman, 1998). Although these models have contributed greatly to an understanding of important aspects of clinical decision-making in nursing, they are limited in describing the broad range of thinking processes required in professional work settings. In addition, they lack descriptive measures that ensure the quality of clinical decision-making in nursing.

An analysis of the South African Nursing Council's disciplinary case-study reports (SANC, 1993-1999) indicates that there is an increase in the number of disciplinary cases that relate to the decisions nurses make while caring for patients (SANC, 1993-1999). From these case study reports, it is clear that the nurse's clinical decision-making is not in line with expectations as reflected in the legal-ethical framework of nursing as a profession. In addition, media reports on the medical mistakes made by health workers stress their gross negligence. Mistakes range from misdiagnosis, mistakes made during the implementation of a prescribed course of therapy and miscommunication, or the lack thereof, among members of the multi-disciplinary health team. In this vein, it can be concluded that clinical decisions made by health workers in general, but by nurses in particular, do not necessarily comply with minimum professional expectations in the delivery of quality nursing care.

To meet these imminent challenges imposed on nurses as decision-makers in a complex, ever-changing and evolving context of health-care delivery, and in improving the quality of clinical decisions made by nurses, a system for quality clinical decision-making in nursing, that depicts the complexities of the process and context within which it occurs, is required.

\section{PURPOSE OF THE ARTICLE}

The purpose of this article is to conceptualise a system for quality clinical decision-making in nursing.

\section{DEFINITION OF KEY CONCEPTS}

\section{A system}

A system refers to an organised collection of complex, interrelated, interdependent decision-making processes, procedures and competencies (knowledge, skills, attitudes and values), used in an interactive-dialectic way and employing follow-up rationality against high contextual complexity to enhance differentiation and quality during clinical decision-making (Von Bertalanffy, 1975:7; Bleecher 1983:68; Betts, 1992:28).

\section{Quality clinical decision-making}

Quality clinical decision-making in nursing refers to the rational, interactive, deliberative, selective, cognitiveaffective, problem solving activity that is followed by nurses in a specific context during the care of an individual. Through a series of transformations, they diagnose health problems based on a comprehensive functional assessment, making goal-directed choices between perceived alternative options and implement these choices in accordance with pre-specified standards that aim to promote the health of the individual, group or community.

\section{Standard}

A standard is a written description or statement of the expected level of performance to reflect excellence (Muller, 1998:242). A standard in this article reflects the desired level of performance in relation to quality clinical decision-making in nursing.

\section{Rational interaction}

Rational interaction in this article refers to a dialogue that the nurses have with members of the multi-disciplinary health team and the patients, through a process of collaboration and consultation and in which they demonstrate a willingness and are able to collaborate, consult and argue the specific clinical decisions in a rational and tolerant way (Rossouw, 1993:293).

In order to conceptualise a system for quality clinical decision-making in nursing, current literature on clinical decision-making was reviewed. Both published and unpublished works that address the factors influencing quality clinical decision-making, its processes and outcomes were analysed and synthesised. A triangulation of literature sources, including primary, classic 
and secondary sources on clinical decision-making, were studied. From this analysis dimensions and concepts pertaining to quality clinical decision-making were conceptualised within a systems-theoretical perspective (Von Bertalanffy, 1950, 1968, 1972). Employing a systems-theoretical perspective justified the complexity associated with quality clinical decision-making in nursing, as an open system. Based on this, a system for quality clinical decision-making in nursing, complying with the essential characteristics of an open system (context, input, dynamism, throughput/process, output and feedback mechanism) (Von Bertalanffy, 1968; Katz \& Kahn, 1996 in Emery, 1969:92-103), was conceptualised.

\section{A SYSTEM FOR QUALITY CLINICAL DE- CISION-MAKING IN NURSING}

A system for quality clinical decision-making in nursing can be conceptualised in different ways. In my view, a system for quality clinical decision-making in nursing, depicting the complexity, inter-relatedness and holistic nature thereof, should be based on a systemstheoretical perspective.

From a systems-theoretical perspective, a system, according to Von Bertalanffy (1975:7), is defined as "complexes of elements in interaction". In support of Von Bertalanffy, Bleecher (1983:68) also defines a system as "an organized collection of interrelated elements characterized by a boundary and functionality... to achieve a common purpose" (Betts, 1992:28). Gharajedaghi and Ackoff (1985:6) describe a system as "a whole that cannot be divided into independent parts; the behavior of the parts and their effects on the whole depends on the behavior of the other parts". Irrespective of the way in which a system is conceptualised, there is a common thread that emerges and focuses on interaction, interrelatedness, interconnectedness, holism, complexity, integration, commonality in function and goal directness as essential characteristics of a system. Clinical decision-making in nursing is an interactive, dynamic and complex problem solving process, which aims to promote the health of the individual, group or community. All these characteristics of clinical decision-making in nursing compare favourably with those of a system. It could therefore be argued that a system for quality clinical decision-making in nursing (Figure 1) should be based on a systems-theo- retical perspective.

\section{SYSTEMS-THEORETICAL PERSPEC- TIVE}

Vickers (1991:46) contended that General Systems Theory is largely a post-war development. Many researchers from both natural and social sciences played a central role in the development of the theory. However, Ludwig von Bertalanffy (1901-1972), a biologist considered by many to be the father of the General Systems Theory, expressed concern in the 1930's about the tendency of natural science disciplines to become increasingly specialised (Letseka in Higgs, 1995:286). Von Bertalanffy (1975:6) remarks, “... as a consequence it is not sufficient to study isolated parts and processes since the essential problems are the organizing relations that result from dynamic interaction of those parts".

According to Treml (in Higgs, 1995:268) human beings, particularly nurses, increasingly experience situations in which their plans of action are obstructed, frustrated or thwarted by the undesired and unexpected subsequent effects of their intended purposes. Consequently, the traditional way of thinking and acting is approaching the limit of its advantageousness. The traditional way of solving problems and making clinical decisions can be briefly characterised as "linear causal thinking". It assumes that all problems are calculable and that for all calculable problems there are causal solutions. If a problem cannot be solved, it is normally assumed that existing knowledge is incomplete or in need of improvement. This way of thinking was shaken by the everincreasing experience of simple solutions, which failed to solve problems. The many undesired effects of modern technology are worrying and people are increasingly realising that the world is much more complicated than previously assumed (Higgs, 1995:268).

\section{Major premises of systems theory}

In its various manifestations, the systems theory can be interpreted as a scientific method for dealing with this problem (Higgs, 1995:268). One single problem common to all approaches is the problem of complexity. According to Higgs (1995:268), the aspect of complexity which would best seem to define the problem involved in systems theory, might be the only point of 


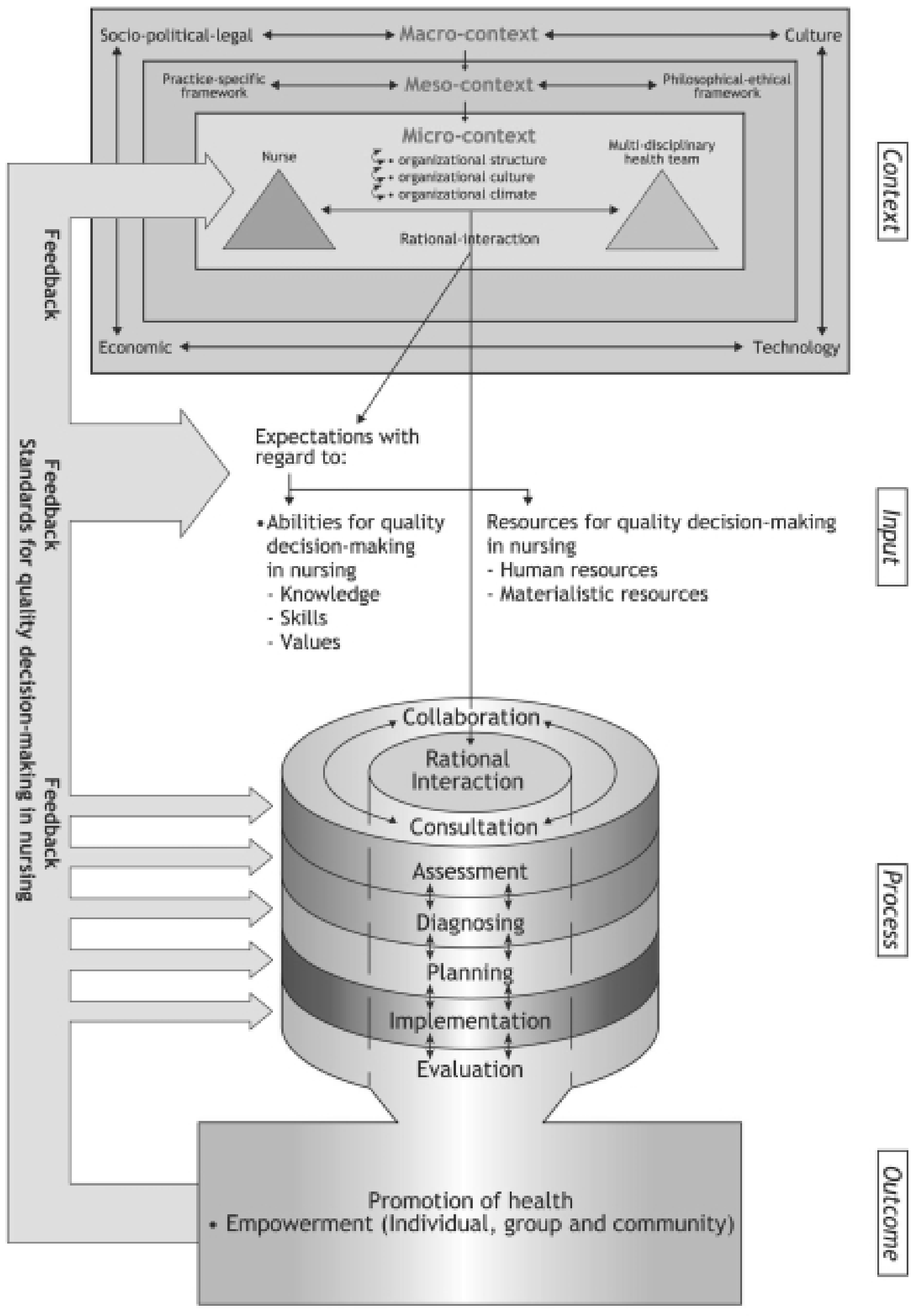

Figure 1: A system for quality decision-making in Nursing 
consensus among the multitude of otherwise very different approaches to the systems theory. It describes the experience of a system that is no longer able to control its environment because imminent constraints make it impossible for each element of the environment to be linked to an element of the system. The environment of a system is in principle more complex than the system itself. In other words, complexity is a measure of the uncertainty and the system's lack of information on its environmental condition.

A system can only fall back upon, recognise and change its environment selectively (Higgs, 1995:268). Therefore, selectivity, after complexity, seems to be the next most important concept in the systems theory. It describes the fact that each system is compelled to select its environmental contacts in ignorance of the complete state of the environment. Since this selection is made without knowledge of the entire range from which to select, it cannot base its rationality on the selecting subject, but only on the system's success. A system acts rationally if it goes about this selectivity in such a way that continued survival is ensured (Higgs, 1995:268-269), implying that for each action of the system there is a follow-up action ("follow-up rationality"). In this vein, the systems theory can even be interpreted as an applied form of this rationality. It tries, against the background of high complexity, to convey follow-up rationality by enhancing the capacity for differentiation and recombination. It does so through interrelated functionality instead of linear causality, relations, configurations, patterns instead of individual elements, things, substances, and contingency instead of necessity, implying that instead of organisation and planning, there are processes of self-organisation and evolution (Gharajedeghi \& Ackoff, 1985:6; Higgs, 1995:269-271).

In understanding a system for quality clinical decisionmaking in nursing, as depicted in Figure 1, a synthetic, rather than analytical thinking from the reader, is required. The successful functioning of a system for quality clinical decision-making in nursing is not the sum of its different components, but rather the interaction and interconnectedness between these components. A description of a system for quality clinical decisionmaking in nursing (see Figure 1) will be provided in accordance with the following components of a system: context, input, dynamic, process, outcome and feedback mechanism.

\section{THE CONTEXT: MULTI-DIMENSIONALITY, MULTI-LEVEL AND DYNAMIC}

The process of transformation influences the context of clinical decision-making in nursing in South Africa. The processes of rationalisation and the restructuring of the health-care services characterise the latter process, which in turn renders the context of clinical decision-making as complex. The complexity of the context is further enhanced by its multi-dimensional, multilevel and dynamic nature. Therefore, in order to understand the complex nature of clinical decision-making in nursing requires that it be examined in a macro-, meso- and micro-context.

\section{The macro-context}

The macro-context of quality clinical decision-making in nursing refers to the current socio-political context within which clinical decisions have to be made. This context has several uncontrolled dimensions, including socio-political-legal, cultural, technological and economic. All these dimensions simultaneously directly or indirectly influence the quality of clinical decisionmaking in both the nurse-patient context (micro-context) and in the meso-context (professional context).

The socio-political-legal dimension is characterised on the one hand by socio-political changes such as the processes of transformation, liberalisation and democratisation, and on the other hand by rival philosophies and values about life in general, but about health in particular. As a result of the transformation process, several structural changes in the form of new legislation have emerged, such as the Constitution of South Africa (Act No. 108 of 1996) in which particular human rights impacting on clinical decision-making are enshrined. More specific to health care and the process of decision-making, the White Paper on the Transformation of the Health Care System (1997(a)) and the White Paper on the Transformation of Public Services (1997(b)) are two important legal frameworks to be considered. However, numerous other new and old existing legal frameworks and policies, generally known among nurses as the ethical-legal framework for nursing practice, can be interpreted as important legislation that directly and indirectly influences the quality of clinical decision-making in nursing (Van Niekerk, 1996:70-80; Kershoff \& McCarthy, 1995:37- 
38).

The cultural dimension refers to an accepted set of values, beliefs and behaviours shared within a social group. As Bate (1994:11) argues, cultures manifest themselves fundamentally through the values, beliefs and assumptions embedded in institutions and organisations. Drennan (1992) defines culture as "the way things are done around here". Therefore, it could be argued that it is culture at individual, group or institutional levels that creates the context for quality clinical decision-making in practice. Kitson, Harvey and McCormack (1998:149159) suggest that context includes "the forces at work which give the physical environment a character and feel", suggesting a direct relationship between context and culture. Culture influences the ways in which people express themselves and therefore also influences the ways in which patients, nurses and health care professionals interact with each other during clinical decision-making (Deloughery, 1998:173-175). Since culture influences every facet of a person's actions, it is understandable that quality clinical decision-making is determined to some extent by cultural beliefs and practices. Culture, Bate (1994:12) argues, "is not something an organisation has but something an organization is; it is a label or metaphor for, not a component of, the total work organization". Culture can therefore be seen as a paradigm, a way of thinking about or viewing quality clinical decision-making within an organisation. It comprises basic assumptions, values, artefacts and creations.

Technology, as a cultural artefact, will continue to proliferate and will demand particular skills from nurses during clinical decision-making. The use of hospital information system configurations, such as on-line, interactive, network and integrative systems continue to increase. Computerised patient records are already evident in some private health-care institutions. All of these technological advances pose implications for the abilities required by the nurse in order to incorporate and apply them during clinical decision-making. Technological advances pose certain economic challenges to any health-care institution (Huston \& Fox, 1998:112). Economic issues are, and will continue to be the driving force of health-care delivery. Re-engineering, which is the fundamental rethinking and radical redesign of business processes to achieve dramatic improvements in contemporary measures of performance such as cost, quality, service and speed, have been the healthcare industry's primary response to unchecked rising health-care costs (Hammer \& Champy, 1993). Furthermore, managed care systems, including pre-paid group practice plans, preferred provider organisations, integrated service networks and independent practice associations, will continue to proliferate. As decisionmakers, nurses cannot ignore the "big business" aspects of health care. The current health-care system must be understood as an economic enterprise (Huston \& Fox, 1998:110). Failure to understand the precepts of business will condemn nurses to passive roles in the health-care business environment, particularly at a time when they should be collaborating in reconstructing and transforming health-care delivery and decisionmaking.

\section{The meso-context}

The meso-context refers to the context between the macro- and micro-contexts of clinical decision-making . As a result, through professional regulatory channels, it functions as a buffer for the micro-context against the influences of the macro-context. The South African Nursing Council (SANC), in terms of the Nursing Act of 1978, Act 50 of 1978, as amended in 1997 (South Africa, 1997), is the recognised body responsible and accountable for regulating the nursing profession. The SANC does so through its legislation, licensing and disciplinary roles and the setting of frameworks, including policies and regulations that govern the practice of the nurse as an independent practitioner.

The two important frameworks embedded in the mesocontext are the practice-specific and philosophical-ethical frameworks that guide clinical decision-making in nursing. Regulations 2598 and 387 are but two important regulations that guide the practice of the nurse in general, but also clinical decision-making in particular. Regulation 2598 describes in broad terms the responsibilities of the nurse during a clinical decision-making situation. Regulation 387 describes rules against which the SANC can hold nurse decision-makers accountable, allowing for disciplinary action in the event of transgression. In terms of both of the aforementioned practice-specific frameworks, nurses, as independent practitioners, who make clinical decisions in collaboration with other applicable members of the multi-professional team, are responsible and accountable for their deci- 
sions. Accountability means, by implication, that nurses should justify their decisions in a rational way. Rationality during clinical decision-making has to do with reasonableness. This means that nurses should justify their clinical decisions based on argumentation. To do this as a professional person implies that the nurse should approach clinical decision-making in a scientific manner, based on certain clinical competencies such as knowledge, skill, attitude and values to ensure the legal, ethical and clinical justifiability of decisions.

\section{The micro-context}

The micro-context refers to the time-spatial situation where the nurse is in interaction with the patient and members of the multi-disciplinary health team with the aim of making clinical decisions to promote the health of the patient. This includes all the settings of healthcare delivery at primary, secondary or tertiary institutional levels (Kitson, et al. 1998:149-151). The organisational landscape of these health care services (namely structure, culture and climate) influences the interaction between the nurse, the members of the multidisciplinary health team and the patient during clinical decision-making. Any organisational landscape can either be a positive or a negative facilitator for the nurse's clinical decision-making. Kitson, et al. (1998:150) are of the opinion that leadership within an organisation summarises the nature of human relationships, such that effective leadership gives rise to clear roles, effective teamwork and effective organisational structures. All of these are conducive circumstances in promoting an environment with a "feel and flavour" of quality. Therefore, in order to achieve quality in clinical decision-making in an organisation that undergoes transformation, the emphasis should be placed on transformational leadership.

Managers as transformational leaders of health-care institutions create a culture that recognises everyone as a leader in clinical decision-making. They inspire staff towards a shared vision of quality and they challenge, stimulate, enable and foster an environment of trust and open communication and collaboration that will foster quality clinical decision-making by nurses in such institutions (Kitson, et al. 1998:155). Therefore, if the emergence of a new paradigm of health-care delivery - in which the nurse adopts the role of an independent decision-maker, collaborator and consultant - is indeed under way, managers need to understand that the nature of organisational structures, climate and culture is likely to change. As a result, the structure, process and outcome of nurses' clinical decision-making will be altered within such health-care organisations (Le Storti, et al. 1999:63). Organisational structures, climate and cultures that are more flexible and responsive to market and socio-political forces should emerge in order to promote quality clinical decision-making by nurses (Carchidi \& Peterson, 2000:2).

On the contrary, both the transformation of health-care systems and the complex nature of the context in which clinical decision-making occur, create a situation where stakeholders in a particular decision-making situation have specific needs and expectations. To achieve quality in clinical decision-making in health-care would require that the expectations of the stakeholder in a particular clinical decision-making situation should be considered. Therefore, the expectations of stakeholders coupled with influences from the macro-, meso- and micro-contexts of clinical decision-making could be regarded as inputs that drive the process of clinical decision-making. In addition, expectations, as either consciously or unconsciously held beliefs of stakeholders, serve as a framework from which clinical predictors or standards to assess the quality of clinical decision-making can be derived. In considering these expectations therefore require that nurses explore the expectations of people involved in a particular clinical decision-making situation.

\section{THE INPUT: EXPECTATIONS ABOUT QUALITY CLINICAL DECISION-MAKING}

Sparacino (1991:138) maintains that nurses should make expert clinical decisions based on reflection, complex reasoning and critical thinking, applying theoretically based knowledge to diverse client situations. This implies that nurses should incorporate the competencies of thinking skills and knowledge with experience and values, which will provide them with the structure to interact rationally and creatively during clinical decision-making. To make quality clinical decisions in nursing requires a multi-disciplinary corpus of knowledge - empirical, ethical, aesthetic and personal skills (Carper, 1978) together with a strong foundation of ethical values and attitudes. All of these will enable the nurse to judge the appropriateness of decisions in a 
given situation. To make quality clinical decisions, the nurse uses critical and reflective thinking skills to integrate both objective and subjective data with knowledge gained from an understanding of subjective experiences of patients.

Complex nurse-patient situations and the individualisation of nursing care will require nurses to follow an eclectic approach to clinical decision-making. This means that they combine suitable knowledge about models and theories from other disciplines that are congruent with, and appropriate for a particular clinical decision-making situation, with experience, skills, ethical values and attitudes to solve patients' problems during decision-making. Quality clinical decision-making in nursing, based on a multi-disciplinary corpus of knowledge, integrating appropriate ethical values, attitudes and skills is most likely to achieve the desired outcome of health promotion and empowerment of the individual, the group and the community.

In addition, clinical competencies provide the cognitive-affective structure that guides clinical decisionmaking in nursing. Furthermore, clinical competencies help nurses to explain "what they know" and the justification for particular decisions that facilitate the promotion of the health of the individual, group or community. Cognitive-affective structural competencies present the nurse with ideal, logical and unique frameworks about the issue to be decided on and the outcome to be achieved. As a result, it structures and provides a systematic approach to assess a particular clinical decision-making situation; identifies and interprets relevant information; formulates diagnoses; generates alternatives and makes choices among them; implements effective nursing actions and evaluates the outcome thereof through rational interactive clinical decisionmaking.

However, clinical competencies alone will not facilitate quality clinical decisions. Human and material resources are necessary to promote and facilitate quality clinical decision-making in nursing. Ultimately, these resources will determine whether certain decisions made by the nurse can be implemented. Therefore, resources are regarded as imperative for quality clinical decision-making in nursing. Together, clinical competencies and resources are frameworks the nurse uses and relies on during clinical decision-making. Clinical competencies and appropriate resources, such as human and material resources, enable the nurse to assess a particular situation on the one hand and recall and apply appropriate procedures and methods to make and implement clinical decisions on the other (Marshall, 1995:39).

Rational interaction is the underlying dynamic that serves as a golden thread during the decision-making process.

\section{DYNAMIC: RATIONAL INTERACTION FOR CLINICAL DECISION-MAKING}

Rational interaction drives the process of quality clinical decision-making in nursing. Rational interaction during clinical decision-making in a period of healthcare transformation is important, as any decision-making situation involves more than one stakeholder. It is also highly probable that rival opinions will exist among stakeholders about what constitutes quality clinical decision-making. Furthermore, nurses, as independent practitioners who make clinical decisions in collaboration with other members of the multi-disciplinary health team, are responsible and accountable for their clinical decisions. This implies that they should be able to justify their decisions on rational grounds by means of logical argumentation.

Rational interaction during clinical decision-making in nursing therefore refers to a dialogue the nurse has with members of the multi-disciplinary health team and the patient through a process of collaboration and consultation. When a decision needs to be made about a specific issue, stakeholders should be willing participants in a dialogue and be able to collaborate, consult and argue the issue in a rational and tolerant manner (Rossouw, 1993:293). During clinical decision-making of this kind, rational argumentation refers to an interactive-communicative process where the nurse applies the methods of verification, justification, criticism and introspection (Chinn, 1985:45-49) in advancing, supporting and modifying claims about a particular decision. Stating arguments in a reciprocal manner, that is understandable to all the stakeholders involved, might facilitate the granting or denying of adherence to particular decisions (Rieke \& Sillars, 1993:1).

The rationality implied here is not the strict rationality 
of positivism, but allows for arguments in which values, culture, religion and emotions are considered during dialogues on clinical decision-making, applying inductive, deductive and retroductive reasoning (Ballard, 1991:39; Robbins, 1980:168; Schwella, 1985:79). Rational arguments are valid means of persuasion that are permitted in the dialogue on clinical decision-making in nursing. Tolerance during collaborative clinical decision-making implies that stakeholders respect each other and recognise that everyone does not merely have a stake, but also a valid contribution to make during a discussion on clinical decision-making. Stakeholders, therefore, have to allow each other the freedom to express their own opinions and to oppose and/or criticise the opinions of their colleagues (Rossouw, 1993:293).

The aim of rational interaction during clinical decisionmaking should not necessarily be to reach consensus, but for stakeholders to demonstrate sensitivity in a particular clinical decision-making situation for the practical, legal, ethical and clinical correctness of certain decisions in order to persuade one another (Rossouw, 1993:294). Deliberation is therefore a critical component of the interaction during clinical decision-making. If differences in persuasion during clinical decision-making are not caused by deficient reasoning, then two or more rival perspectives/opinions regarding certain evidence brought to the clinical decision-making situation could each be based on valid rational grounds. Implying consensus could not be considered to be a realistic and viable outcome for decision-making in nursing. The best one could hope for is that stakeholders with rival opinions and perspectives in such a dialogue would be willing to reformulate their own positions in the light of their standpoints on the particular issue. Rather than attacking the standpoints of other stakeholders on which their respective points of view are based, stakeholders should be focusing on the practical, legal, ethical and clinical correctness of the argument, as presented by the different stakeholders in the dialogue. During this type of rational interaction in clinical decision-making in nursing, stakeholders will become aware of, and sensitive to, the implications of their decisions, which they either have not foreseen or have not fully realised in the past (Rossouw, 1993:294).

\section{THE PROCESS: QUALITY CLINICAL DE- CISION-MAKING IN NURSING}

From a systems perspective, Kramer and De Smit (1977:38) define a process as "a transformation or a series of transformations brought about in the throughput of a system as a result of which the throughput is change in position, shape, size, version or some other respect".

Clinical decision-making in nursing is described as a systematic process that begins with the assessment and diagnoses of a problem and ends with the evaluation of the choices formulated in a plan and implementation of actions. The process of a model for quality clinical decision-making in nursing is based on the following classical theoretical frameworks of clinical decision-making: the hypothetical-deductive method, analytic, information-processing theory (Baker, 1997:4344; Buckingham \& Adams, 2000:981-983; Higgs \& Jones, 1995:6; Newell \& Simon, 1972; Thompson, 1999:1223), decision analysis theory (Raiffa, 1968) and intuitive decision-making (Meerabeau, 1992:108-112; Cioffi, 1997:203; Thompson, 1999:1224). Theories based on theoretical perspectives of the Dreyfus model of skill acquisition, as applied by Benner (1984) and Benner and Tanner (1987), together with the model of pattern recognition (Cioffi, 1997:203-205; Offredy, 1998:992), are employed in an integrated discussion on the process of clinical decision-making in nursing. In the field of clinical decision-making, experts regard the aforementioned theoretical frameworks as classic works. For this reason they form the basis for the following discussion.

During clinical decision-making, nurses finds themselves in a situation of uncertainty, which occurs as the nurses become aware of a change in the usual circumstances in a particular situation. This state of uncertainty is enhanced by a number of variables impacting on the situation. Nurses would like to achieve certainty as soon as possible by reducing uncertainty in the situation. To reduce uncertainty, nurses use either a "piece-meal", cognitive structuring or intuitive approach to clinical decision-making (Cioffi, 1997:203207; Fonteyn, 1999; Tabak \& Bar-Tal, 1996:1). In employing a "piece-meal" approach to clinical decisionmaking, nurses demonstrate vigilant behaviour that includes systematic assessment of the situation, thereby identifying the variables impacting thereon. An unbiased assimilation based on their existing knowledge framework - enables nurses to distinguish between relevant 
and irrelevant assessment data and to diagnose the problem to be solved during clinical decision-making (Driscoll, Hamilton \& Sorrentino, 1991:494-500). On the contrary and, according to Neuberg and Newson (1993:113), by using cognitive-structuring processes, nurses "use abstract mental presentations, such as schemata, prototypes, scripts, attitudes and stereotypes, that are simplified generalizations of previous experience" to categorise information and diagnose the problem to be solved during clinical decision-making.

Cognitive structuring enables the nurse to attain certainty most efficiently as this is relatively automatic, effortless and quicker than vigilant behaviour or analytical processing (Baker, 1997:43; Brewer, 1988; Shiffrin \& Schneider, 1977) that occurs in a "piece-meal" approach. This categorisation process facilitates certainty, as it enables the nurse to filter out irrelevant information. Furthermore, it enables the nurse to add previously stored information that is necessary to attain certainty about the clarity and validity of the diagnosed problem (Higgs \& Jones, 1995:6; Fiske \& Linville, 1980 in Tabak \& Bar-Tal, 1996). However, even when nurses use a "piece-meal' process, assessment information has to be assimilated in their knowledge structures to become useful. Thus, both a "piece-meal" and a cognitive-structuring approach to clinical decisionmaking are essential for assessing and diagnosing problems. Certainty is thus achieved, insofar as the problem that is being dealt with. In this vein, Bunder (1962:2951) postulates that uncertainty is caused by an individual's inability to adequately structure or categorise information. Maximal use of an existing cognitive schema is therefore an efficient method for decision-making, as it requires few cognitive resources (Tabak \& Bar-Tal, 1996:2).

During clinical decision-making, the nurses clarify and verify the problem, design a plan within which goals and objectives are formulated, make a deliberate judgement and choose between perceived alternatives based on his/her framework of knowledge. Specific strategies, tools and techniques for clinical decision-making are considered, generated, explored and critically analysed. A choice is made for the best possible action, tools, technique or strategy and these possible ramifications are considered and decided upon. On the part of the nurses, this process can be viewed as a deliberation to frame the decision-making process, by using the vari- ables associated with the problem to guide them. A frame refers to nurses' knowledge framework, which they bring to bear on a particular decision-making context in order to endow that context with meaning (Beach, 1990:51). This frame is divided into partitions, namely knowledge, which includes situational, declarative, procedural, strategic, circumstantial, axiomatic and relational knowledge, skills and values. According to Beach (1990:51), each of these partitions is keyed to a particular situation within a particular context or domain. Thus, the knowledge, skills and values in a particular partition specify the meaning of a particular clinical decision-making context. To access the particular partition within the frame, the nurses employ a process of framing. According to Beach (1997:17), framing involves a process where the nurses contemplate and embed observed events against a particular partition of their knowledge framework with the aim of endowing a particular clinical decision-making situation with meaning (Beach, 1997:17). This memory probe mechanism of framing that is employed by the nurse during clinical decision-making is a deliberate way of accessing the appropriate knowledge, skills and value partition for a given situation (Beach, 1990:51).

Deliberation occurs within the frame to clarify the problem, to generate alternative options and to consider their implications, making a choice and ultimately reaching a decision (Beach, 1990:50). Deliberative thinking during clinical decision-making enables the nurse to clarify the meaning of the observed data within the context, to diagnose the problem and to identify and choose between alternative actions, after having considered their ramifications. Furthermore, it allows the nurse to draw an analogy of possible features of similar decisions and to identify tools, strategies and techniques with which the desired outcome of clinical decision-making can be attained in the most effective and efficient way (Beach, 1990:6). Deliberative thinking enables the nurse to achieve a changed perspective of the situation and the issue to be decided upon.

As part of the deliberation process, the nurse, who participates in a patient encounter, gathers preliminary information about the patient. This stage in clinical decision-making is also called the cue acquisition stage. Following this stage, the nurse formulates a preliminary problem or hypothesis. This problem is related to data gathered and short-term memory-based cues. The 
interpretation stage, which follows the problem formulation stage, involves the nurse interpreting the cues gathered during the assessment or acquisition stage and classifying them as either confirming, refuting or not contributing to the initial problem formulated. From cue logic, which involves the employment of skills, such as the thinking skills of induction, deduction and retroduction, the nurse finally identifies, explores, analyses and compares alternatives with their outcomes. By comparing the clinical data or generated alternatives with one another and judging them against the possible outcome thereof based on certain criteria, the nurse draws a conclusion on the best solution for the problem. According to Pesut and Herman (1998:31), this side-by-side comparison of alternatives to their outcome, based on certain criteria, creates a match or mismatch test condition, using the criteria of clinical and contextual feasibility, acceptability and vulnerability, significance, congruence and utility to judge a particular alternative (Cooke \& Slack, 1991 :282; Thompson, 1999:1223). Based on their value systems, the nurses are thus able to determine the extent to which an alternative achieves the outcome of clinical decision-making in the most effective and efficient way. What is left is for the nurses to choose the most appropriate alternative, which is regarded as the decision that they reach (Cooke \& Slack, 1991:282).

The final decision that the nurses reach is the conclusion that they draw from the comparison between the alternative and the outcome thereof, based on pre-specified criteria or evidence (Pesut \& Herman, 1998:31-32). After the decision is made, the nurse should implement this decision to assess whether it was effective and efficient. Implementation is therefore the next phase of clinical decision-making. During this phase, the nurse draws on the available resources and appropriate actions formulated as part of the planning phase to implement the decision. A variety of actions can be implemented to achieve the outcome of the decision. These actions may include supportive measures, therapeutic measures, continuous data collecting and monitoring of the health status of the individual, health promotion and health maintenance activities, including teaching, co-ordination of care, reporting, recording and consultation (Wilkinson, 1992:185-215; Muller, 1996:132 \& 182; Walsh, 2002:12). Implementing decisions helps the nurse and the other members of the multi-disciplinary health team to make the transition from the initial uncertain state to the desired certain outcome state (Herman \& Pesut, 1998:32). By implementing the best possible decision dictated by the situation, the nurse is able to achieve the outcome of decision-making in nursing, namely the promotion of health and the empowerment of individuals, groups and communities. During the evaluation phase, the nurse ascertains whether the desired outcome of decision-making has been achieved. The evaluation stage is crucial, as evaluation leads to modifications of both the decision or the process followed (Jacobs \& Pelfrey, 1995:47). During the evaluation phase, the nurse also compares the effect of the decision on the basis of quality outcome criteria.

\section{OUTCOME: HEALTH PROMOTION AND EMPOWERMENT}

The outcome of clinical decision-making in nursing has to do with the promotion of health and the empowerment of the individual, group or community. Moving beyond the biomedical model of decision-making and an individual lifestyle perspective, WHO defines health as "a resource for living ... a positive concept ... the extent to which an individual or group is able to realise aspirations, to satisfy needs, and to change or cope with the environment"(WHO, 1986). According to Hatrick (1998:219) and Brown (1991:441-442), health promotion can be conceptualised as concern for the creation of living conditions in which persons' experience of health is increased and they are able to take control of and improve their health. From this perspective, disease prevention is a secondary goal. This implies that a person's health can still be promoted through a process of clinical decision-making, without necessarily reducing the prevalence of disease or specific risk factors, thereby extending the scope of clinical decisionmaking from an exclusive bio-medical approach to a more inclusive health promotion or wellness approach.

Within a system for quality clinical decision-making in nursing, health promotion is considered an emancipatory and empowerment process characterised by "power with" relations and active participation of all relevant stakeholders involved in clinical decision-making. Empowerment is regarded as a process of enabling people to increase control over, and to improve their health status (Purdey, Adhikari, Robinson \& Cox, 1994 in Mokwena, 1997:67). This implies that power corre- 
lates positively with a person's health status. The health of individuals can therefore be promoted by empowering them during clinical decision-making. Mokwena (1997:67) mentions that the success of several health programmes has been attributed to the process of individual, group and community empowerment.

After a decision has been implemented and evaluated, measures should be employed to improve on the input, process, outcome and some contextual factors of future or existing clinical decisions. For this reason, standards for clinical decision-making in nursing are proposed as such a feedback mechanism.

\section{FEEDBACK: STANDARDS FOR QUALITY CLINICAL DECISION-MAKING}

Feedback refers to a mechanism or system that is employed during which the outcome of a process is monitored and compared with its input, with the aim of remediation (Lapatra, 1975:16; Banathy, 1996:49). To promote and improve the quality of clinical decisionmaking in nursing, standards for clinical decision-making can be regarded as such a feedback mechanism. A standard refers to a written description that reflects the desired level of performance associated with the characteristic of excellence for measuring, evaluating and remediating actual performance during clinical decisionmaking in nursing (Muller in Booyens, 1998:606). The following is an example of an outcome standard for clinical decision-making:

There is written evidence that clinical decision-making in nursing facilitates the empowerment of the individual, group or community as measured by the following criteria:

- Individuals, groups or communities are able to make informed decisions on identifying and prioritising problems that affect them.

- They are able to identify and challenge factors that render them powerless during decision-making.

- They have developed leadership skills that enable them to sustain health promotion.

- They have increased confidence and competence in handling decisions that affect them.

- They are able to sustain health promotion even after outside help is withdrawn.

- They have established their own decision-making support networks and therefore rely less on out- side help and formal structures.

- They are able to communicate identified needs to decision-makers.

- They have developed effective communication skills and are able to solve conflict during decision-making.

Using standards for clinical decision-making in nursing as a feedback mechanism to monitor the process of clinical decision-making, by comparing the process with the input and the outcome thereof and by implementing remedial action will facilitate the quality of clinical decision-making in nursing. A system for quality decision-making in nursing can therefore be regarded as an open system that can maintain itself by exchanging information with its surroundings that are in a state of constant change of its internal structure, context and process (Badenhorst, 1993:210-211).

\section{CONCLUSION}

Traditional clinical decision-making was usually associated with the nursing process in nursing. The initial four-step nursing process was designed to organise the thinking of nurses so that the problems encountered by patients could be anticipated and quickly solved. This approach of problem and solution generation of nursing process was transformed because of a concern for and a need to understand nursing diagnosis and diagnostic reasoning or clinical decision-making. This approach in the nursing process related to diagnosis and reasoning and was derived from research that used information processing models and decisionmaking theory. However, with the shift in health care delivery, attention from problems and diagnosis to specification and measurement of outcomes became apparent. A system for quality clinical decision-making in nursing capitalises on the nursing process heritage. By considering these changes and the complexities associated with clinical decision-making in nursing, the system accommodates recent knowledge development activities in nursing, such as developments in nursing classification systems and the classification of nursing-sensitive patient outcomes during clinical decisionmaking. Furthermore, a new model of clinical decisionmaking can also influence the development of middlerange theories in nursing. A system that anchors and provides linkage among the elements of the nursing process with that of contextual, clinical competencies, 
intervention, outcomes and feedback, can facilitate the development of clinical and theoretical propositions that provide the foundation for theories of clinical decisionmaking in nursing.

Nursing literature commonly separates decision-making into one of two theoretical perspectives: the positivistic perspective, as exemplified by information-processing theory or piece-meal approaches, and a postmodernistic perspective, as typified by the intuitive approach of Benner and the Dreyfusses (Benner, 1984). Neither of these two perspectives offer an integrative approach to clinical decision-making that is able to reconcile the tension between them in the clinical reality in which nurses' practice. The conceptualisation of a system for quality clinical decision-making offers such an approach in which these two approaches can be used complementary to each other to achieve quality clinical decisions. In addition, many decision-making models end with an evaluation of decisions, without offering a mechanism to facilitate the quality of future clinical decisions. With the conceptualisation of a system for quality clinical decision-making, the authors propose such a feedback mechanism in the form of standards, in order to promote or improve the quality of nurses' clinical decisions.

\section{ACKNOWLEDGEMENT}

Dr Ebin Arries would hereby like to recognise the contribution to his doctoral study of his promoter and mentor, the late Professor Annatjie Botes, from which this article has originated.

\section{REFERENCES}

Aspinal, M 1979: Use of decision tree to improve accuracy of diagnosis. Nursing Research, 28:182-185.

Badenhorst, DC 1993: Chaos theory: Some new metaphors for education (In: Kros, CJ \& Herman, HD 1992: Educational change in Southern Africa: Proceedings of the 1992 Annual Conference of the South African Comparative and History of Education Society (SACHES), June 1992).

Baker, JD 1997: Phenomenography: An alternative approach to researching the clinical decision-making of nurses. Nursing Inquiry, 4:41-47.

Ballard, H 1991: Decision-making in local government: selected theoretical perspectives. Politikon, 23(2)72-84.

Banathy, BH 1996: Contemporary Systems Thinking: Designing social systems in a changing world. New York: Plenum.

Bate, P 1994: Strategies for cultural change. Oxford: Butterworth Heinemann.

Beach, LR 1990: Image theory: Decision-making in personal and organizational contexts. New York: John Wiley.

Beach, LR 1997: The psychology of decision-making people in organizations. London: Sage.

Benner P 1984: From novice to expert: Excellence and power in clinical nursing practice. Reading, Massachusetts: AddisonWesley.

Benner, P \& Tanner, C 1987: Clinical judgement: how expert nurses use intuition. American Journal of Nursing, 87(1):23-31.

Betts, F 1992: How systems thinking applies to education. Education Leadership, 50(3):39-41.

Bleecher, H 1983: Systems theory effects on practice in education. Education, 104(1):67-71

Booyens, SW 1998: Dimensions of Nursing Management; second edition. Cape Town: Juta.

Brown, ER 1991: Community action for health promotion: A strategy to empower individuals and communities. International Journal of Health Services, 21(3):441-456.

Brewer, MB 1988: A dual process model of impression information (In: Srull, TK \& Wyer, RS eds 1988: Advances in social cognition, 1. New Jersey: Lawrence Erlbaum. pp1-36.). Buckingham, CD \& Adams, A 2000: Classifying clinical decisionmaking: A unifying approach. Journal of Advanced Nursing, 32:981-989.

Bunder, S 1962: Intolerance of ambiguity as a personality variable. Journal of Personality, 30:29-51.

Carchidi, DM \& Peterson, MW 2000: Emerging organisational structures. Planning for Higher Education, 28, Spring:1-16.

Carper, BA 1978: Fundamental patterns of knowing in Nursing. Advances in Nursing Science, 1(1):13-23.

Carnavali DL \& Thomas, MD 1993: Diagnostic reasoning and treatment decision-making in nursing. Philadelphia: Lippincott. Chinn, PL 1985: Theory and nursing; $2^{\text {nd }}$ edition. St Louis: CV Mosby.

Cioffi, J 1997: Heuristics, servants to intuition in clinical decisionmaking. Journal of Advanced Nursing, 26:203-208.

Cooke, S \& Slack, N 1991: Making management decisions; second edition. New York: Prentice Hall.

Deloughery, SD 1998: Clinical decision-making: theory and practice. Nursing Standard, 18(36):47-52.

Drennan, D 1992: Transforming company culture. London: McGraw-Hill.

Driscoll, DM; Hamilton, DL \& Sorrentino, RM 1991: Uncertainty orientation and recall of person-descriptive information.

Personality and Social Psychology Bulletin, 17:494-500. 
Emery, FE ed 1969: Systems thinking: selected readings. England: Penquin Books.

Fonteyn, ME 1999: Thinking strategies for nursing practice. New York: Lippincott.

Gharajedaghi, I \& Ackoff, RL 1985: Toward a systems theory of organizations. Seaside California: Intersystems.

Hammer, M \& Champy, J 1993: Re-engineering the corporation: A manifest for business revolution. New York: Harper Collins.

Hatrick, G 1998: Developing health promotion practices: A transformative process. Nursing Outlook, 46(5):219-225.

Higgs, J \& Jones, M 1995: Clinical reasoning in the health professions. Oxford: Butterworth-Heinemann.

Higgs, P ed 1995: Meta-theories in Philosophy of Education. Johannesburg: Heinemann.

Gordon M 1994: Nursing diagnosis: Process and application;

2nd edition. New York: McGraw-Hill.

Huston J \& Fox, M 1998: Management decision-making for nurses: 118 case studies. Philadelphia: Lippincott.

Jacobs, SM \& Pelfrey, S 1995: Decision support systems: Using computers to help manage. Journal of Nursing Administration (JONA), 25(2):46- 52.

Kerschoff, GJ \& McCarthy, CL 1995: Democratization and economic policy: The experience of selected countries. Politikon, 22(1):36-51.

Kilian, JG 1995: Critical care costs: Our challenge for the future.

South African Medical Journal of Critical Care, 85(5):419420.

Kitson, A; Harvey, G \& McCormack, S 1998: Approaches to implementing research in practice. Quality Health Care, 7:149- 159.

Krairiksh, M \& Anthony, MK 2001: Benefits and outcomes of staff nurses' participation in decision-making. Journal of Nursing

Administration (JONA), 31(1):1623.

Kramer, NJTA \& De Smit, J 1977 : Systems thinking. Leiden: Martinus Nijhof Social Sciences Division.

Krejci, JW 1999: Changing roles in nursing. Journal of Nursing Administration, 29(3):21-29.

Lapatra, JW 1975: Health care systems: Evaluation criteria. New York: Charles $C$ Thomas.

Le Storti, AJ; Cullen, PA; Hanzlik, EM; Michiels, JM; Piano, LA; Ryan, PL \& Johnson, W 1999: Creative thinking in nursing education: Preparing for tomorrow's challenges. Nursing Outlook, 47(2):62-66.

Lilford, RJ; Pauker, SG; Braunholtz, DA \& Chard, J 1998: Decisionanalysis and the implementation of research findings. British Medical Journal, 317:405-409.

Marshall, SP 1995: Schemas in problem solving. Cambridge: University Press.

Meerabeau, L 1992: Tacit nursing knowledge: an untapped re- sources or a methodological headache? Journal of Advanced Nursing, 17:108-112.

Mokwena, K 1997: Empowerment as a tool for community health development. Community Health Association of South Africa (CHASA). Journal of Comprehensive Health, 8(2):66-70.

Moorhead, S ed. \& Huber, DG 1997: Nursing roles: Evolving or recycled? London: Sage.

Muller, ME 1996: Nursing dynamics. Johannesburg: Heinemann Muller, M 1998: Nursing dynamics; $2^{\text {nd }}$ edition. Sandton: Heinemann. Newell, A \& Simon, HA 1972: Human problem solving. Englewood Cliffs, NJ: Prentice Hall.

Offredy, M 1998: The application of decision-making concepts by nurse practitioners in general practice. Journal of Advanced Nursing, 28(5):988-1000.

Pesut, DJ \& Herman, J 1998: OPT: Transformation of nursing process for contemporary practice. Nursing Outlook, January/February:29-36.

Raiffa, H 1968: Decision-analysis: Introductory lectures on choices under uncertainty. Massachusetts: Addison-Wesley.

Republic of South Africa 1996: The Constitution of the Republic of South Africa. Act no. 200 of 1996, as amended. Pretoria: State Press.

Republic of South Africa 1997(a): White Paper for the transformation of the health system in South Africa. Notice 667 of 1997. Pretoria: State Press.

Republic of South Africa 1997(b): White Paper on transforming public service delivery (Batho Pele). Notice 1459 of 1997.

Pretoria: State Press.

Rieke, RD \& Sillars, MO 1993: Argumentation and critical decisionmaking; $3^{\text {rd }}$ edition. New York: Harper Collins.

Robbins, SP 1980: Management; third edition. Englewood Cliffs, NJ: Prentice-Hall.

Robbins, SP 1991: The administrative process; $2^{\text {nd }}$ edition. New Jersey: Prentice-Hall.

Rossouw, GJ 1993: Moral decision-making admist moral dissensus: A postmodern approach to moral decision-making in business. Koers, 58(3):283-298.

Schwella, E 1985: Hulpmiddels vir effektiewe beleidbepaling en besluitneming. Stellenbosch: University of Stellenbosch. Shiffrin, RM \& Schneider, W 1977: Controlled and automatic human information processing. II. Perceptual learning, automatic attending, and a general theory. Psychological

Review, 84:127-190.

South Africa (Republic) 1997: Nursing Amendment Act 1997. Pretoria: Government Printer.

South African Nursing Council, 1993-1999: Disciplinary reports. Pretoria: SANC.

Sparacino, P 1991: The reciprocal relationship between practice and theory. Clinical Nurse Specialist, 5(3):138. 
Tabak, N \& Bar-Tal, Y 1996: Clinical decision-making of experienced and novice nurses. Western Journal of Nursing Research, 18:534-547.

Tanner, C; Padrick, KP; Westfall, UE \& Putzier, DJ 1987: Diagnostic reasoning strategies of nurses and nursing students. Nursing

Research, 36(6):358-363.

Thompson, C 1999: A conceptual treadmill: the need for "middle ground" in clinical decision-making theory in nursing. Journal of Advanced Nursing, 30(5):1222-1229.

Van Niekerk, A 1996: Filosoof op die markplein. Kaapstad: Tafelberg.

Vickers, JM 1991: An examination of the scientific mode of enquiry in politics with special reference to systems theory in the works of Easton, Almond, Kaplan and Deutsch. London: Garland Von Bertalanffy, L 1950: An outline of General systems theory. British Journal of Philosophy of Science, 1:134-164.

Von Bertalanffy, L 1968: General systems theory: foundations, development,applications. New York: George Braziller. Von Bertalanffy, L 1972: General systems theory - a critical review. (In: Beishon, J \& Peters, G eds 1972: Systems behavior. London: Open University Press).

Von Bertalanffy, L 1975: General systems theory. (In: Ruben, RD \& Kin, JY eds 1975: General systems theory and human communication. New Jersey: Hayden).

Walsh, M ed. 2002: Watson's clinical nursing and related sciences; $6^{\text {th }}$ edition. Edinburgh: Baillière Tindall.

Wilkinson, JM 1992: Nursing process in action: A critical thinking approach. Kansas: Addison-Wesley Nursing. World Health Organization 1986: Ottawa Charter for Health Promotion. Ottawa, Ontario, Canada: Health \& Welfare Canada. 